\title{
Successful management of a case of Cerebral Salt Wanting Syndrome (CSWS) related hyponatremia
}

\author{
Seifeldin Yahia, Jennifer Clayton, Nottingham University Hospital, QMC, UK
}

\section{Contents}

43 year old lady with a history of Rheumatoid Arthritis (On Sulfasalazine and Infliximab IV every 8/52), was brought in to our hospital following a collapse. She had had acute onset of headache six weeks prior to admission with nausea, vomiting and blurred vision but her symptoms had gradually resolved. Her GCS on arrival was 5 . Subsequent CT scan brain showed acute right-sided subdural haematoma and subarachnoid haemorrhage and was indicative of coning. She was taken to theatre immediately for decompressive craniotomy and evacuation of her acute subdural haematoma. She was transferred to the ITU.

On day 4 post operatively, she was hyponatremic with sodium $127 \mathrm{mmol} / \mathrm{l}$ (base line Sodium was $144 \mathrm{mmol} / \mathrm{l}$ preoperatively). Her sodium continued to fall progressively, reaching $118 \mathrm{mmol} / \mathrm{l}$ at day 6 . Investigations showed TSH $1.1 \mathrm{mu} / \mathrm{l}$, urine Osmolality $512 \mathrm{mosmol} / \mathrm{kg}$, plasma Osmolality $241 \mathrm{mosmol} / \mathrm{kg}$, urine sodium $167 \mathrm{mmol} / \mathrm{l}$, urea 2.2 $\mathrm{mmol} / \mathrm{l}$, creatinine $39 \mathrm{umol} / \mathrm{l}, \mathrm{K} 3.5 \mathrm{mmol} / \mathrm{l}$. She was not dry clinically and her CVP was 5-6 cm H2O. It was difficult to differentiate between Cerebral Salt Wasting Syndrome (CSWS) and SIADH. She was cautiously treated with hypertonic saline and her hyponatremia corrected over a couple of days to $134 \mathrm{mmol} / \mathrm{l}$

\section{Discussion:}

We report a case of hyponatremia secondary to assumed cerebral salt wanting syndrome which was successfully and wisely treated with hypertonic saline in the ITU. The cause of hyponatremia post brain injury is often difficult to ascertain. We recommend patients should be carefully clinically and biochemically assessed. If this is supportive of cerebral salt wasting syndrome then fluid replacement should be commenced and cautious use of hypertonic saline considered. Hypertonic saline at a rate between $50-150 \mathrm{ml} / \mathrm{h}$ as a bolus initially, and then review as per current standard of care, so as not to increase the sodium concentration by more than an average of $0.5 \mathrm{mmol} / \mathrm{l} / \mathrm{hour}$ or an increase no greater than $10 \mathrm{mmol} / \mathrm{l}$ in the first 24 hours. This is to prevent the development of osmotic demyelination.

\begin{tabular}{|lll|}
$\begin{array}{l}\text { Table } 1 \\
\text { Biochemical markers: comparison of SIADH and CSW }\end{array}$ & & \\
\hline Biochemical marker & SIADH & \\
\hline Extracellular fluid volume & Normal to high & Low \\
\hline Urinary sodium level & $>40 \mathrm{mEq} / \mathrm{L}$ & $>40 \mathrm{mEq} / \mathrm{L}$ \\
\hline Serum uric acid level & Low & Low \\
\hline Initial fractional excretion of urate & High & High \\
\hline Fractional excretion of urate after correction & Normal & High \\
\hline Urinary osmolality & High & High \\
\hline Serum osmolality & Low & Low \\
\hline Blood urea nitrogen/creatinine level & Low to normal & high \\
\hline Serum potassium level & Normal & Normal to high \\
\hline Central venous pressure & Normal to high & Low \\
\hline Pulmonary capillary wedge pressure & Normal to high & Low \\
\hline Brain natriuretic peptide level & Normal & High \\
\hline Treatment & Water restriction & Fluids and/or m \\
\hline CSVV = cerebral sail wasting; SIADH = syndrome of inappropriate antidiuretic hormone. & \\
\hline
\end{tabular}

\begin{tabular}{|l|}
\hline Table 2 \\
Causes of cerebral salt wasting \\
\hline - Subarachnoid haemorrhage \\
\hline - Head trauma \\
\hline - Intracranial neoplasm \\
\hline - Metastatic neoplasm \\
\hline - Infections or carcinomatous \\
\hline - Encephingitis \\
\hline - Central nervous system surgery \\
\hline
\end{tabular}

